\title{
Antibioottien vaikutus lietelannan metaanintuottoon
}

Satu Ervasti ${ }^{1)}$, Sari Luostarinen ${ }^{2)}$, Minna Hartonen ${ }^{3)}$, Iida Loivamaa ${ }^{3)}$, Pertti Koivisto ${ }^{3)}$

1) Luonnonvarakeskus, Uudet liiketoimintamahdollisuudet, Eteläranta 55, 96300 Rovaniemi, satu.ervasti@luke.fi

${ }^{2)}$ Luonnonvarakeskus, Uudet liiketoimintamahdollisuudet, Vuorimiehentie 2, 02150 Espoo, sari.luostarinen@luke.fi

${ }^{3)}$ Elintarviketurvallisuusvirasto Evira, Mustialankatu 3, 00790 Helsinki, etunimi.sukunimi@evira.fi

Mikrobilääkkeille resistenttien bakteerikantojen yleistyminen on kasvava maailmanlaajuinen ongelma. Suomessa antibioottien käyttö tuotantoeläimillä on useisiin muihin maihin nähden vähäistä, mutta silti potentiaalinen riski. Lääkittyjen eläinten lantaan erittyy mikrobilääkejäämiä ja resistenttejä bakteerikantoja, ja lannan lannoitekäyttö voikin olla riski niiden leviämiseen peltoon ja edelleen luontoympäristöön. Lannan tehokas käyttö edistää ravinnekiertoa maataloudessa ja Suomikin tavoittelee lisää lannan prosessointia. Keskitetyistä laitoksista lääkejäämät ja resistentit bakteerikannat voivat levitä entistä laajemmalle. Toisaalta prosessointi voi mahdollistaa lääkejäämien ja resistenttien kantojen tuhoutumisen. Biokaasuprosessi mahdollistaa yhtäaikaisen lannan ravinteiden ja energian hyödyntämisen. Mikrobilääkkeet voivat kuitenkin häiritä sen mikrobiologiaa. Toisaalta lääkeaineet voivat myös hajota täysin tai osin prosessin aikana.

Kahden Suomessa yleisesti eläinlääkityksessä käytetyn antibiootin, oksitetrasykliinin ja siprofloksasiinin, vaikutusta lypsykarjan lietelannan metaanintuottoon tutkittiin eri pitoisuuksina ja seoksina. Kokeella selvitettiin, miten ja millä pitoisuuksilla antibiootit vaikuttavat metaanintuottoa alentavasti.

Tutkimus toteutettiin 30 vrk panostoimisella kokeella käyttäen automatisoitua metaanipotentiaalin mittauslaitteistoa AMPTS II (Bioprocess Control AB, Ruotsi). Kokeessa seurattiin lypsykarjan lietelannan hajoamista ja ymppinä oli maatilan biokaasulaitoksen mädäte. Antibiootit lisättiin lannan ja ympin seokseen vesiliuoksina. Kokeessa oli 14 koejäsentä. Lietelantakontrollin ja pelkän ympin lisäksi oli 12 erilaisia antibioottikäsittelyjä: 4 oksitetrasykliinipitoisuutta (10-500 mg kg-1), 4 siprofloksasiinipitoisuutta (2-50 mg $\mathrm{kg}^{-1}$ ) sekä 4 seosta, joissa siprofloksasiinipitoisuus oli 10 ja $20 \mathrm{mg} \mathrm{kg}^{-1}$ ja oksitetrasykliinipitoisuus 50 ja $100 \mathrm{mg} \mathrm{kg}^{-1}$.

Lietelannan metaanipotentiaali oli $218 \mathrm{~m}^{3} \mathrm{CH}_{4} \mathrm{MgVS}^{-1}$ (kontrolli). Eniten lannan hajoamista esti oksitetrasykliinipitoisuus $500 \mathrm{mg} \mathrm{kg}^{-1}$, joka tuotti metaania 48\% vähemmän, $105 \mathrm{~m}^{3} \mathrm{CH}_{4} \mathrm{MgVS}^{-1}$. Oksitetrasykliinin pitoisuudella $10 \mathrm{mg} \mathrm{kg}^{-1}$ ei havaittu vaikutusta metaanintuottoon, mutta seuraavaksi suuremmalla annoksella $50 \mathrm{mg} \mathrm{kg}^{-1}$ metaanintuotto heikkeni selvästi $\left(170 \mathrm{~m}^{3} \mathrm{CH}_{4} \mathrm{MgVS}^{-1}\right)$. Samoin siprofloksasiinin pienimmällä annoksella $2 \mathrm{mg} \mathrm{kg}^{-1}$ ei vaikutusta havaittu, mutta $10 \mathrm{mg} \mathrm{kg}^{-1}$ vähensi metaanintuottoa $\left(197 \mathrm{~m}^{3} \mathrm{CH}_{4} \mathrm{MgVS}^{-}\right.$ ${ }^{1}$ ). Seoskäsittelyiden pienimmällä tutkitulla pitoisuusyhdistelmällä (oksitetrasykliini $50 \mathrm{mg} \mathrm{kg}^{-1}+$ siprofloksasiini $10 \mathrm{mg} \mathrm{kg}^{-1}$ ) metaanintuotto oli $161 \mathrm{~m}^{3} \mathrm{CH}_{4} \mathrm{MgVS}^{-1}$.

Antibioottien vaikutus metaanintuottoon oli selkeä tiettyjen pitoisuuksien ylittyessä; mitä suurempi antibioottiannostus oli, sitä vähemmän metaania muodostui. Tutkitut antibioottipitoisuudet olivat kuitenkin selvästi korkeampia kuin suomalaisessa lypsykarjan lietelannassa samassa tutkimuksessa havaittiin (oksitetrasykliini $5 \mu \mathrm{g} \mathrm{kg}{ }^{-1}$, siprofloksasiini alle määritysrajan $3 \mu \mathrm{g} \mathrm{kg}^{-1}$ ). Näillä pitoisuuksilla metaanintuoton ei havaittu häiriintyvän.

Asiasanat: antibiootti, biokaasu, lietelanta

\section{Johdanto}

Mikrobilääkkeille resistenttien bakteerikantojen yleistyminen on kasvava maailmanlaajuinen ongelma (WHO 2014). Suomessa antibioottien käyttö tuotantoeläimillä on useisiin muihin maihin nähden vähäistä, mutta silti potentiaalinen riski. Lääkittyjen eläinten lantaan erittyy suuri osuus käytetyistä mikrobilääkkeistä joko sellaisenaan tai metaboliatuotteina ja lisäksi resistenttejä bakteerikantoja (Marshall ja Levy 2011). 
Lannan lannoitekäyttö voikin olla riski niiden leviämiseen peltoon ja edelleen luontoympäristöön. Lannan tehokas käyttö kuitenkin edistää ravinnekiertoa maataloudessa ja lannan käytön tehostaminen on keskeisessä roolissa Suomen hallituksen kärkihankkeena olevassa kiertotalouden edistämisessä. Suomikin tavoittelee lannan tehokkaampaa hyödyntämistä, mikä voi tarkoittaa myös suurempia prosessointiyksiköitä. Keskitetyistä lannan prosessointilaitoksista lääkejäämät ja resistentit bakteerikannat voivat levitä entistä laajemmalle alueelle. Toisaalta prosessointi voi mahdollistaa lääkejäämien ja resistenttien kantojen tuhoutumisen.

Biokaasuprosessi mahdollistaa yhtäaikaisen lannan ravinteiden ja energian hyödyntämisen. Se perustuu useiden mikrobiryhmien yhteistyönä tapahtuvaan orgaanisen aineksen hajotukseen lopulta metaaniksi $\left(\mathrm{CH}_{4}\right)$. Mikrobilääkkeet voivat kuitenkin häiritä sen mikrobiologiaa, mutta toisaalta lääkeaineet voivat myös hajota täysin tai osin prosessin aikana.

Kahden Suomessa yleisesti eläinlääkityksessä käytetyn mikrobilääkkeen, oksitetrasykliinin (OTC) ja siprofloksasiinin (CIP), vaikutusta biokaasuprosessin mikrobiologiaan, eli metaanintuottoon tutkittiin eri pitoisuuksilla erikseen ja lääkeaineiden seoksina. Panostoimisilla kokeilla selvitettiin, miten ja millä pitoisuuksilla antibiootit vaikuttavat metaanintuottoa alentavasti. Tutkittavana syöttömateriaalina oli lypsykarjan lietelanta, koska nautatiloilla käytetään Suomessa suhteellisen paljon mikrobilääkkeitä verrattuna muihin eläinlajeihin (Thomson ym. 2008). Tutkittavien mikrobilääkepitoisuuksien perustana käytettiin hankkeen aiemmissa osioissa selvitettyjä navettaympäristössä ja lannoissa havaittuja OTC- ja CIP-pitoisuuksia. Lisäksi korkeampia pitoisuuksia lannoissa ja biokaasukokeissa kartoitettiin aiempien tutkimusten perusteella kirjallisuudesta.

Tutkimus toteutettiin osana Nami-hanketta (Mikrobilääkeresistenssi ja -jäämät nautatiloilla - vaikutukset ympäristöön ja terveyteen), MMM 2015-2017. Hankkeessa selvitettiin, miten mikrobilääkkeille resistentit bakteerit ja resistenssigeenit sekä mikrobilääkkeet aineenvaihduntatuotteineen kulkeutuvat Suomen olosuhteissa lääkityistä naudoista lantaketjun kautta tilaympäristöön ja edelleen muuhun ympäristöön. Antibioottien käyttäytymistä (hajoaminen/säilyminen) biokaasuprosessissa tutkittiin laboratoriomittakaavassa simuloidussa lantaketjussa.

\section{Materiaalit ja menetelmät}

Tutkimus toteutettiin kahdella erillisellä 30 vrk panostoimisella kokeella (kokeet A ja B) käyttäen automatisoitua metaanipotentiaalin mittauslaitteistoa AMPTS II (Bioprocess Control AB, Ruotsi). Kokeissa seurattiin Luken Minkiön navetan lypsykarjan lietelannan hajoamista metaaniksi ja ymppinä oli Luken Maaningan 90 eläimen maitotilan biokaasulaitoksen mädäte. Lannan ja mikrobiympin orgaanisen kuivaaineen (VS) suhde panoskokeessa oli 0.75:1. Metaanipotentiaalikoe suoritettiin kolmena rinnakkaisena käsittelynä lämpötilassa $37{ }^{\circ} \mathrm{C}$. Muodostuvan metaanin tilavuusmittaus perustui nesteensyrjäytykseen, jonne metaani johdettiin biokaasun hiilidioksidin poiston jälkeen. Antibiootit lisättiin lannan ja ympin seokseen liuoksina, joista OTC oli liuotettu pelkästään veteen ja CIP liuotukseen käytettiin lisäksi 1 molaarista natriumhydroksidia annostuksella $20 \mathrm{~g} \mathrm{~kg}^{-1}$. Molemmissa kokeissa oli antibioottikäsiteltyjen pullojen lisäksi mukana lietelantakontrollin ilman antibioottilisäystä sekä pelkkä mikrobiymppi.

Ensimmäiseen kokeeseen (A) mikrobilääkekäsittelyt valittiin Minkiön navettaympäristössä ja lannoissa havaittujen pitoisuuksien sekä kirjallisuudessa esitettyjen, havaintoja korkeampien pitoisuuksien perusteella. Minkiön navetalla tehdyissä näytteenotoissa $(n=4)$ lietelannan CIP-pitoisuudet olivat alle

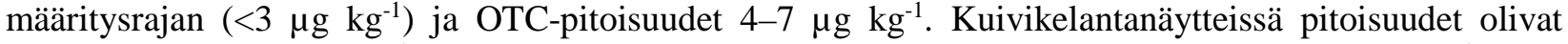
korkeimmillaan $137 \mu \mathrm{g} \mathrm{kg}^{-1}$ (CIP + sen aineenvaihduntatuote enrofloksasiini ENR) ja OTC $91 \mu \mathrm{g} \mathrm{kg}^{-1}$. Sekä siprofloksasiiniä että oksitetrasykliiniä tutkittiin panoskokeessa neljällä eri pitoisuudella sekä yhdellä yhteiskäsittelyllä. Testatut CIP-pitoisuudet pulloissa olivat 0.01; 0.1; 1 ja $2 \mathrm{mg} \mathrm{kg}^{-1}$. OTC-pitoisuudet olivat 
0.1; 1 ; 3 ja 10 mg kg-1 . Lisäksi oli yksi yhteiskäsittely, CIP-pitoisuus $1 \mathrm{mg} \mathrm{kg}^{-1}$ ja OTC-pitoisuus 3 mg $\mathrm{kg}^{-1}$.

Panoskoe uusittiin myöhemmin samana vuonna korkeammilla antibioottipitoisuuksilla (koe B). Kokeessa B oli 14 koejäsentä, joista 12 oli erilaisia antibioottikäsittelyjä. Siprofloksasiinin pitoisuudet olivat 2-50 mg $\mathrm{kg}^{-1}$ ja oksitetrasykliinin 10-500 mg kg-1. Lisäksi mukana oli 4 antibioottien seosta. Kokeessa B suunnitellut ja toteutuneet antibioottipitoisuudet on esitetty taulukossa 2. Kyseisessä kokeessa mitatut OTC-pitoisuudet olivat noin 33\% korkeampia kuin laskennalliset pitoisuudet. Ero menee kuitenkin OTC-analyysin mittausepävarmuuden piiriin.

Taulukko 1. Kokeen B käsittelyt (1-14) sekä suunnitellut ja toteutuneet antibioottien pitoisuudet ( $\left.\mathrm{mg} \mathrm{kg}^{-1}\right)$

\begin{tabular}{|c|c|c|c|c|c|c|}
\hline \multirow[b]{2}{*}{ Käsittely } & \multirow[b]{2}{*}{ Ymppi } & \multirow[b]{2}{*}{$\begin{array}{c}\text { Naudan } \\
\text { lietelanta }\end{array}$} & \multicolumn{2}{|c|}{ Suunniteltu pitoisuus $\left(\mathrm{mg} \mathrm{kg}^{-1}\right)$} & \multicolumn{2}{|c|}{ Analysoitu pitoisuus $\left(\mathrm{mg} \mathrm{kg}^{-1}\right)$} \\
\hline & & & Siprofloksasiini & Oksitetrasykliini & Siprofloksasiini & Oksitetrasykliini \\
\hline B-1 & $x$ & & & & & \\
\hline B-2 & $x$ & $x$ & & & & \\
\hline B-3 & $x$ & $x$ & 2 & & 2 & \\
\hline B-4 & $x$ & $x$ & 10 & & 10 & \\
\hline B-5 & $x$ & $x$ & 20 & & 19 & \\
\hline B-6 & $x$ & $x$ & 50 & & 47 & \\
\hline B-7 & $x$ & $x$ & & 10 & & 14 \\
\hline B-8 & $x$ & $x$ & & 50 & & 69 \\
\hline B-9 & $x$ & $\mathrm{x}$ & & 100 & & 138 \\
\hline B-10 & $x$ & $x$ & & 500 & & 726 \\
\hline B-11 & $x$ & $\mathrm{x}$ & 10 & 50 & 11 & 67 \\
\hline B-12 & $x$ & $x$ & 20 & 100 & 21 & 112 \\
\hline B-13 & $x$ & $x$ & 10 & 100 & 10 & 127 \\
\hline B-14 & $x$ & $x$ & 20 & 50 & 23 & 65 \\
\hline
\end{tabular}

\section{Tulokset}

Ensimmäisessä koejaksossa (A) ei havaittu metaanintuoton alentumista tai hidastumista millään tutkitulla mikrobilääkepitoisuudella tai -yhdistelmällä. Panosreaktorit ilman lääkeainelisäystä tuottivat lietelannasta metaania $212 \mathrm{~m}^{3} \mathrm{Mg}^{-1} \mathrm{VS}$, ja mikrobilääkkeitä sisältäneissä panosreaktoreissa metaanintuotto oli 202-243 $\mathrm{m}^{3} \mathrm{Mg}^{-1} \mathrm{VS}$. Koetta jatkettiin suuremmilla antibioottipitoisuuksilla (koe B), koska haluttiin selvittää, inhiboiko lannassa olevat pitoisuudet prosessia ja millä pitoisuustasolla inhibitiota alkaa tapahtua.

Lietelannan metaanipotentiaali kontrollinäytteessä kokeessa (B) oli $218 \mathrm{~m}^{3} \mathrm{Mg}^{-1} \mathrm{VS}$. Taulukossa 2 on esitetty lannan metaanintuottopotentiaalit 30 vrk panoskokeessa eri antibioottikäsittelyillä, ja kuvissa 1-3 on esitetty siprofloksasiini-, oksitetrasykliini- sekä näiden yhteiskäsittelyiden kumulatiiviset metaanintuotot orgaanista ainesta kohti esitettynä. Eniten lannan hajoamista inhiboi käsittely B-10, eli korkein oksitetrasykliinipitoisuus, jossa metaanintuottopotentiaali oli vain $105 \mathrm{~m}^{3} \mathrm{Mg}^{-1} \mathrm{VS}$. 


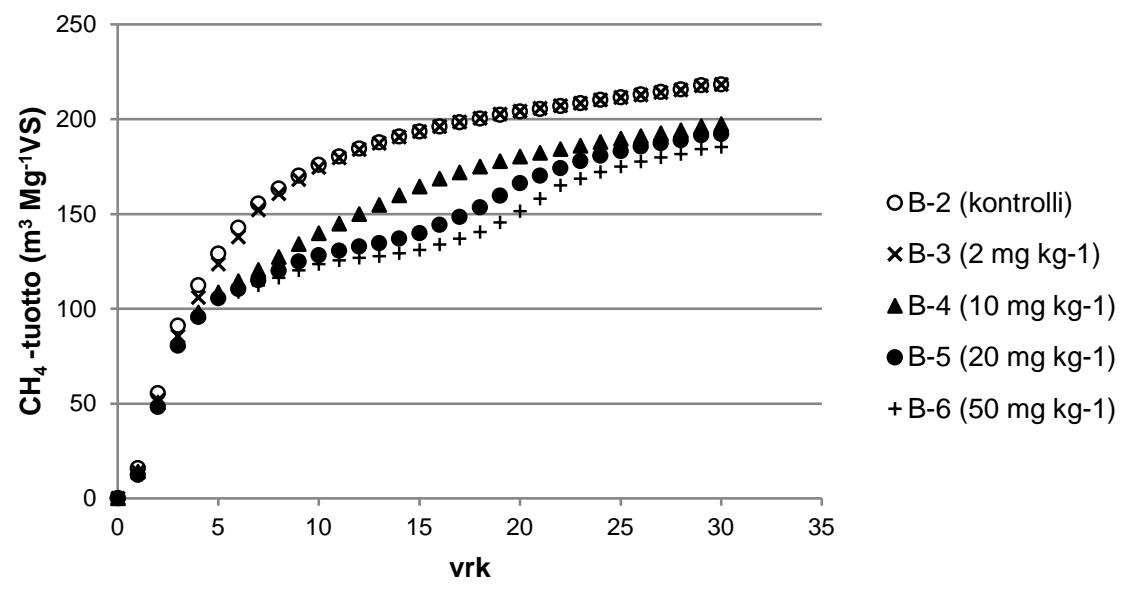

Kuva 1. Lannan kumulatiivinen VS-kohtainen metaanintuotto eri siprofloksasiinipitoisuuksilla

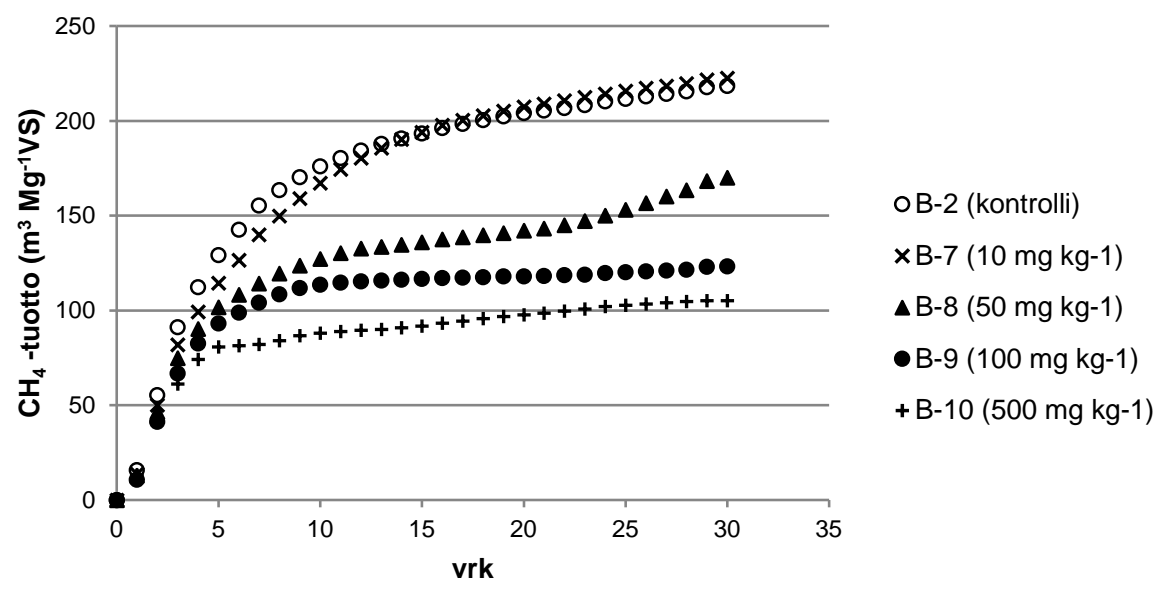

Kuva 2. Lannan kumulatiivinen VS-kohtainen metaanintuotto eri oksitetrasykliinipitoisuuksilla

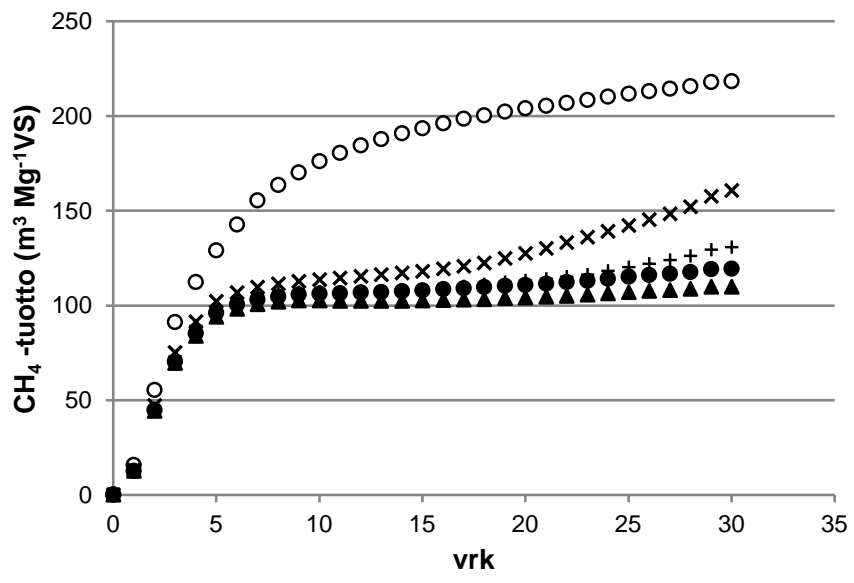

OB-2 (kontrolli)

×B-11 (CIP $10 \mathrm{mg} \mathrm{kg}-1+$ OTC $50 \mathrm{mg} \mathrm{kg-1)}$

$\Delta$ B-12 (CIP $20 \mathrm{mg} \mathrm{kg-1}+$ OTC $100 \mathrm{mg} \mathrm{kg}-1$ )

-B-13 (CIP 10 mg kg-1 + OTC 100 mg kg-1)

+ B-14 (CIP 20 mg kg-1 + OTC 50 mg kg-1)

Kuva 3. Lannan kumulatiivinen VS-kohtainen metaanintuotto siprofloksasiinin (CIP) ja oksitetrasykliinin (OTC) yhteiskäsittelyissä 
Siprofloksasiinin pienimmällä pitoisuudella (käsittely B-3) ei vaikutusta havaittu, mutta seuraavaksi suurin pitoisuus $10 \mathrm{mg} \mathrm{kg}^{-1}$ (käsittely B-4) vähensi metaanintuottoa (197 $\mathrm{m}^{3} \mathrm{Mg}^{-1} \mathrm{VS}$ ). Korkeimmalla tutkitulla CIP-pitoisuudella, käsittely B-6, metaanituotto oli $185 \mathrm{~m}^{3} \mathrm{Mg}^{-1} \mathrm{VS}$. Samoin kuin siprofloksasiinilla, oksitetrasykliinin pienimmällä pitoisuudella, käsittely B-7, ei havaittu vaikutusta metaanintuottoon, mutta seuraavaksi suuremmalla pitoisuudella, käsittely B-8, metaanintuotto heikkeni selvästi (170 m $\left.\mathrm{Mg}^{-1} \mathrm{VS}\right)$. OTC-käsittelyiden suurimmalla pitoisuudella, käsittely B-10, metaanintuotto oli $105 \mathrm{~m}^{3} \mathrm{Mg}^{-1} \mathrm{VS}$. Seoskäsittelyiden pienimmällä tutkitulla pitoisuusyhdistelmällä (käsittely B-11) metaanintuotto oli $161 \mathrm{~m}^{3} \mathrm{Mg}^{-}$ ${ }^{1}$ VS, ja vastaavasti suurimmalla pitoisuusyhdistelmällä (käsittely B-12) $110 \mathrm{~m}^{3} \mathrm{Mg}^{-1} \mathrm{VS}$.

Taulukko 2. Lietelannan kumulatiiviset metaanintuotot (30 vrk) eri mikrobilääkekäsittelyillä tuorepainoa (FM), kuiva-ainetta (TS) ja orgaanista kuiva-ainetta (VS) kohti laskettuna, keskihajonnat VS-kohtaiselle tulokselle sekä metaanintuottopotentiaalin ja metaanintuoton inhibition osuus kontrollikäsittelyn B-2 tuottoon verrattuna

\begin{tabular}{|c|c|c|c|c|c|}
\hline \multirow[b]{2}{*}{$\begin{array}{c}\text { Käsittel } \\
\mathrm{y}\end{array}$} & \multicolumn{3}{|c|}{$\mathrm{CH}_{4}$-tuotto } & \multirow{2}{*}{$\begin{array}{c}\mathrm{CH}_{4} \text {-tuoton osuus } \\
\text { kontrollista }\end{array}$} & \multirow{2}{*}{$\begin{array}{c}\begin{array}{c}\mathrm{CH}_{4} \text {-tuoton } \\
\text { inhibitio }\end{array} \\
\% \\
\end{array}$} \\
\hline & $\mathrm{m}^{3} \mathrm{Mg}^{-1} \mathrm{FM}$ & $\mathrm{m}^{3} \mathrm{Mg}^{-1} \mathrm{TS}$ & $\mathrm{m}^{3} \mathrm{Mg}^{-1} \mathrm{VS}$ & & \\
\hline B-2 & 9.6 & 175 & $218 \pm 8.7$ & 100 & 0 \\
\hline B-3 & 9.6 & 175 & $218 \pm 0.5$ & 100 & 0 \\
\hline B-4 & 8.7 & 158 & $197 \pm 1.4$ & 90 & 10 \\
\hline B-5 & 8.5 & 154 & $192 \pm 4.6$ & 88 & 12 \\
\hline B-6 & 8.2 & 148 & $185 \pm 2.0$ & 85 & 15 \\
\hline B-7 & 9.8 & 178 & $223 \pm 3.4$ & 102 & -2 \\
\hline B-8 & 7.5 & 136 & $170 \pm 12.4$ & 78 & 22 \\
\hline B-9 & 5.4 & 99 & $123 \pm 0.6$ & 56 & 44 \\
\hline B-10 & 4.6 & 84 & $105 \pm 1.3$ & 48 & 52 \\
\hline B-11 & 7.1 & 129 & $161 \pm 6.1$ & 74 & 26 \\
\hline B-12 & 4.8 & 88 & $110 \pm 4.4$ & 50 & 50 \\
\hline B-13 & 5.3 & 96 & $119 \pm 5.3$ & 55 & 45 \\
\hline B-14 & 5.8 & 105 & $131 \pm 3.0$ & 60 & 40 \\
\hline
\end{tabular}

\section{Tulosten tarkastelu}

Antibiootit inhiboivat metaanintuottoa selkeästi tiettyjen mikrobilääkepitoisuuksien ylityttyä. Kokeessa A, jossa pitoisuudet olivat alhaisia, metaanintuoton vähenemistä ei havaittu millään testatulla pitoisuudella. Sen sijaan kokeessa B antibioottien vaikutus metaanintuottonopeuteen havaittiin jo kokeen alussa; mitä suurempi antibioottiannostus oli, sitä vähemmän metaania muodostui. Eniten lannan hajoamista inhiboi käsittely B-10, eli korkein oksitetrasykliinipitoisuus, jossa metaanintuotto oli 52\% vähemmän kuin kontrollilla. Metaanintuottojen osuudet verrattuna kontrolliin ovat taulukossa 2.

Siprofloksasiinikäsittelyissä inhibition raja oli CIP-pitoisuuksien 2 ja $10 \mathrm{mg} \mathrm{kg}^{-1}$ välillä; $10 \mathrm{mg} \mathrm{kg}^{-1}$ CIPpitoisuudella metaanintuotto inhiboitui $10 \%$. CIP-käsittelyissä pitoisuuksilla 20 ja $50 \mathrm{mg} \mathrm{kg}$ oli $^{-1}$ havaittavissa myös metaanintuotannon uudelleen aktivoitumista kokeen kuluessa (Kuva 1). Fluorokinolonien, joihin siprofloksasiini kuuluu, vaikutuksia biokaasuprosessiin on tutkittu huomattavasti vähemmän kuin tetrasykliinien vaikutuksia. Metaanintuoton häiriintymistä on kuitenkin havaittu jatkuvatoimisesta prosessista enrofloksasiinilla pitoisuudella $40 \mathrm{mg} \mathrm{kg}^{-1} \mathrm{VS}$ (Bauer ym. 2014). Liu ym. (2013) tutkivat panoskokeissaan siprofloksasiinin vaikutusta nimenomaan metanogeneesiin ja havaitsivat sen inhiboituvan selvästi CIP-pitoisuuksilla 80-100 $\mathrm{mg} \mathrm{l}^{-1}$. 
OTC:n aiheuttaman metaanintuoton inhibition raja oli pitoisuuksien 14 ja 69 mg kg-1 välillä; 14 mg kg-1 OTC-pitoisuus ei aiheuttanut metaanintuoton vähenemistä, mutta $69 \mathrm{mg} \mathrm{kg}^{-1}$ OTC-pitoisuudella lannan metaanintuotto oli 78\% kontrollista (inhibitio 22\%). OTC-pitoisuudella 138 mg kg-1 (käsittely B-9) metaanintuotto oli 56 \% kontrollista (inhibitio 44\%). Havaittu metaanintuoton häiriintyminen OTC:n vaikutuksesta oli pääosin hieman vähäisempää kuin useissa kirjallisuudessa esitetyissä tutkimustuloksissa. Arikan ym. (2006) mukaan mikrobilääkittyjen nautojen lannalla tehdyissä panoskokeissa metaanintuotto laski 27\% kontrollista jo OTC-pitoisuudella $9.8 \mathrm{mg} \mathrm{kg}^{-1}$. Sianlannalla tehdyssä kokeessa OTC:n ja klooritetrasykliinin (CTC) yhteiskäsittelyllä (molempien lääkeaineiden pitoisuus $50 \mathrm{mg} \mathrm{l}^{-1}$ ) metaanintuoton inhibitio oli 56.5\% (Alvarez ym. 2010). Beneregaman ym. (2013) raportoimassa termofiilisessä naudanlannan kokeessa metaanintuoton inhibitio oli tätä koetta vastaava, OTC-pitoisuuksilla 30, 60 ja $90 \mathrm{mg} \mathrm{l}^{-1}$ inhibitio oli vastaavasti 20.9; 29.7 ja 31.4\% verrattuna kontrolliin. Toisaalta Lallai ym. (2002) kokeessa edes pitoisuuksien $125 \mathrm{mg} \mathrm{OTC} \mathrm{l}^{-1}$ ja $250 \mathrm{mg} \mathrm{OTC} \mathrm{l}^{-1}$ ei havaittu vaikuttavan metaanintuottoon sianlannalla.

Yhteiskäsittelyillä CIP+OTC metaanintuoton inhibitio oli voimakkaampi kuin kummankaan antibiootin kanssa yksinään samoilla pitoisuuksilla. Tämä oli odotettavissa kokonaisantibioottipitoisuuden noustessa korkeammaksi.

Eroihin biokaasuprosessia häiritsevissä OTC- ja CIP-pitoisuuksissa vaikuttavat ainakin käytetyn ympin ja tutkitun lannan ominaisuudet ja antibiooteille altistumisen historia sekä ymppi:substraatti -suhde. Mikrobiston tottuminen, antibioottien hajoaminen prosessin aikana ja mahdolliset vaihtoehtoiset metaboliareitit voivat myös selittää prosessin selviämistä korkeillakin mikrobilääketasoilla.

Käytännössä kaikki tutkitut mikrobilääkkeiden pitoisuudet olivat selvästi korkeampia kuin suomalaisessa lypsykarjan lietelannassa samassa tutkimuksessa havaittiin (oksitetrasykliini $5 \mu \mathrm{g} \mathrm{kg}^{-1}$, siprofloksasiini alle määritysrajan $3 \mu \mathrm{g} \mathrm{kg}^{-1}$ ). Näillä pitoisuuksilla metaanintuoton ei havaittu häiriintyvän.

\section{Johtopäätökset}

Antibioottien käytön aiheuttamat häiriöt naudan lietelannan biokaasuprosessiin ja sen metaanintuottoon Suomessa havaituilla lannan mikrobilääketasoilla ovat näiden panoskokeiden perusteella epätodennäköistä. Mikäli mikrobilääkejäämiä sisältävä lanta ja esim. antibioottimaito käsitellään erikseen, metaanintuoton häiriöt voisivat olla mahdollisia. Antibiooteilla oli kuitenkin havaittavissa selkeä metaanintuottoa haittaava vaikutus tiettyjen pitoisuustasojen ylittyessä. Vaikka vaikutukset metaanintuottoon vaativat hyvin korkeita mikrobilääkkeiden pitoisuuksia, tulisi mikrobilääkkeiden esiintyminen lannassa ottaa silti vakavasti huomioon, olipa lanta tarkoitus prosessoida tai ei. Mikrobilääkejäämien ja -resistenssin leviäminen ympäristöön voi aiheuttaa odottamattomia vaikutuksia ekosysteemeihin.

\section{Kirjallisuusviitteet}

Álvarez , J., Otero, L., Lema, J.M. \& Omil, F. 2010. The effect and fate of antibiotics during the anaerobic digestion of pig manure. Bioresource Technology 101: 8581-8586.

Arikan, O., Sikora, L., Mulbry, W., Khan, S., Rice, C. \& Foster, G. 2006. The fate and effect of oxytetracycline during the anaerobic digestion of manure from therapeutically treated calves. Process Biochemistry 41: 1637-1643.

Bauer, A., Lizasoain, J., Nettmann, E., Bergmann, I., Mundt, K., Klocke, M., Rincón, M., Amon, T., Piringer, G. \& Winckler, C. 2014. Effects of the antibiotics Chlortetracycline and Enrofloxacin on the anaerobic digestion in continuous experiments. BioEnergy Research 7: 1244-1252

Beneragama, N., Lateef, S.A., Iwasaki, M., Yamashiro, T. \& Umetsu, K. 2013. The combined effect of cefazolin and oxytertracycline on biogas production from thermophilic anaerobic digestion of dairy manure. Bioresource Technology 133: 23-30.

Lallai, A., Mura, G. \& Onnis, N. 2002. The effects of certain antibiotics on biogas production in the anaerobic digestion of pig waste slurry. Bioresource Technology 82: 205-208. 
Liu, Z., Sun, P., Pavlostathis, S.G., Zhou, X. \& Zhang, Y. 2013. Inhibitory effects and biotransformation potential of ciprofloxacin under anoxic/anaerobic conditions. Bioresource Technology 150: 28-35

Marshall, B.M. \& Levy, S.B. 2011. Food animals and antimicrobials: impacts on human health. Clinical Microbiology Reviews 24: 718-733.

Thomson, K., Rantala, M., Hautala, M., Pyörälä, S. \& Kaartinen, L. 2008. Cross-sectional prospective survey to study indication-based usage of antimicrobials in animals: Results of use in cattle. BMC Veterinary Research 4:15. WHO 2014. Antimicrobial resistance: global report surveillance 2014.

http://www.who.int/drugresistance/documents/surveillancereport/en/. Viitattu 30.11.2017. 